Therax (1964), 19, 343.

\title{
Anepithelial lung cyst
}

\author{
H. R. S. HARLEY AND T. J. OTTO ${ }^{1}$ \\ From Sully Hospital, near Cardiff
}

A case of anepithelial cyst of the lung removed by surgery is presented.

A man aged 49 years was admitted to Sully Hospital on 26 April 1963. He gave a history of chest symptoms since childhood and of a severe attack of pneumonia four years previously. Since then he had developed progressive shortness of breath and attacks of wheeziness. Two months before admission he had a severe attack of bronchitis, and collapse of the right upper lobe was diagnosed at the Chest Clinic. He was admitted to Cefn Hirgoed Hospital where he remained for two weeks and was treated conservatively with some improvement. On 5 April 1963 he had another attack of bronchitis, and arrangements were made for his admission to Sully Hospital.

On admission his general condition was good. There was no cyanosis or clubbing of the fingers, and he was not apparently short of breath. The trachea was deviated to the left. Air entry over the right upper lobe was diminished. There was hyperresonance over the right upper lobe. The heart sounds were normal, the blood pressure was $170 / 90 \mathrm{~mm}$. $\mathrm{Hg}$, and the pulse rate was $90 /$ minute, the rhythm being regular. Radiological examination of the chest showed a large solitary cyst in the region of the right upper lobe (Fig. 1a and $b$ ).

On 7 May 1963 right thoracotomy was carried out. The pleural space was free and there was a very large bulla attached to the apical segment of the right upper lobe but it was not within the lung substance. The right upper lobe presented three fairly complete foetal fissures, one of which seemed to be within the anterior segment, while the other two were thought to be between the apical and posterior segments and within the posterior segment respectively. The area of lung between the latter two fissures was consolidated, being firm, somewhat nodular, and bluish in colour. A series of small bullae was present at the site of the lower margin of the anterior

\footnotetext{
1 Permanent address: Second Surgical Clinic, Medical Academy, Warsaw.
}

segment of the right upper lobe. There was considerable emphysema of the medial segment of the right middle lobe. The remaining lung appeared normal.

The large apical bulla was easily removed by blunt dissection without creating any bronchial fistula. It appeared to have no real attachment to the substance of the right upper lobe. The consolidated area of the posterior segment of the right upper lobe was removed on a single, fairly large bronchus by the normal segmental resection technique. The marginal bullae were resected beyond a Brock's clamp by the wedge technique. The pleural cavity was drained by apical and basal tubes.

After the operation the patient's lung expanded fully and rapidly. He progressed well, and the operation wound healed within 10 days. $\mathrm{He}$ was discharged home on 25 May 1963.

He was seen as an out-patient on 17 June and 30 September 1963, when he was completely well and clinically very satisfactory. A chest radiograph showed no abnormality (Fig. 2).

\section{PATHOLOGY}

Macroscopically the specimen submitted consisted of the wall of a large air-containing cyst, paperthin in the main, but with some areas of thickening up to $3 \mathrm{~mm}$. The segment removed separately was collapsed, fibrosed, and bronchiectatic. There was no macroscopic evidence of tuberculosis. Microscopically the cyst wall was lined by collagen, and beneath this there was a heavy infiltration of lymphocytes and plasma cells with occasional Russell bodies (Fig. 3). The lung showed bronchiectasis with dense round-cell infiltration and fibrosis. There were also numerous plasna cells and many Russell bodies.

Respiratory function tests performed before and two months after operation are shown in the Table.

These findings demonstrate a post-operative increase in vital capacity, due to a decrease in residual volume, and an improvement in the R.V./ 


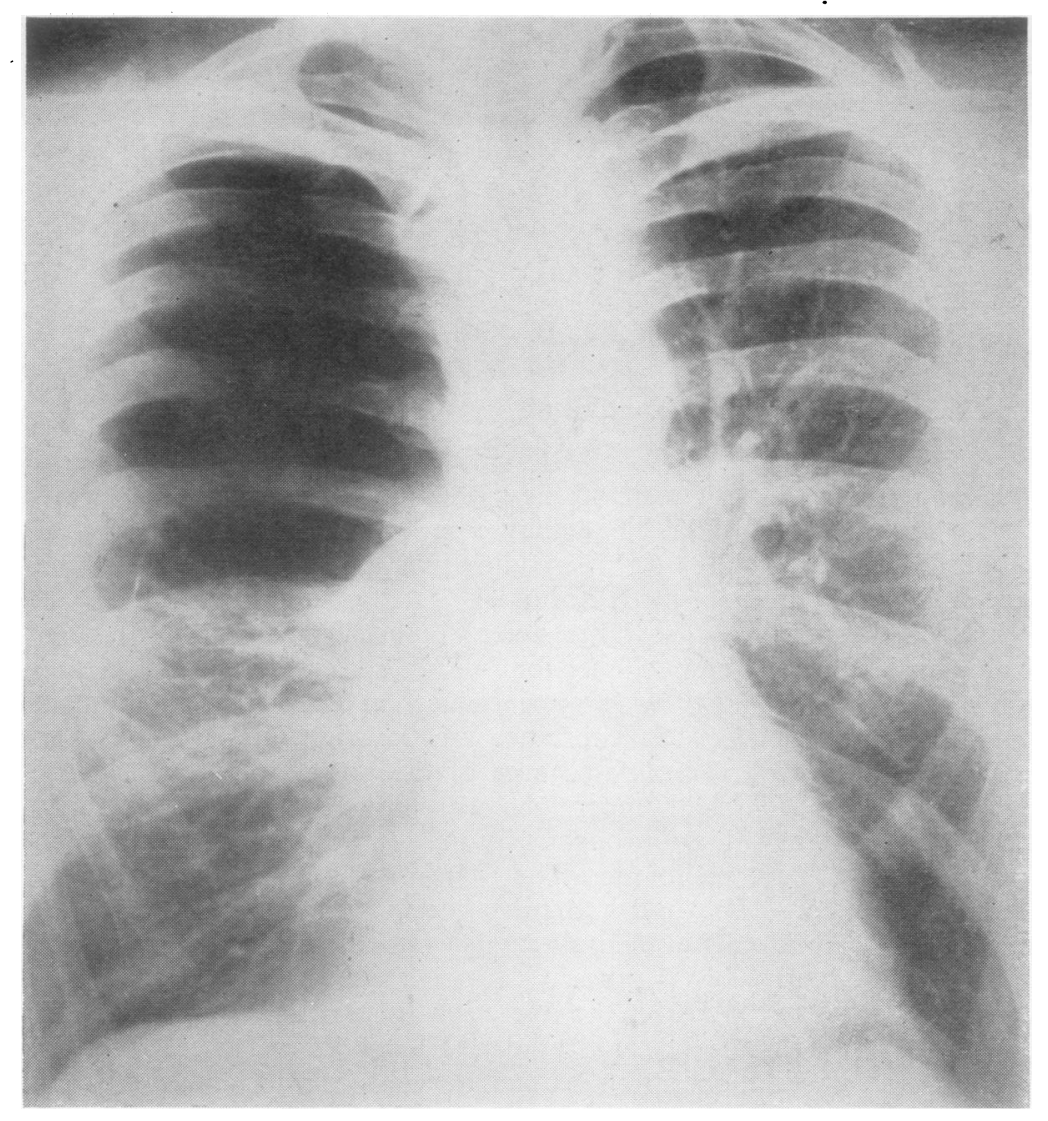

FIG. 1. Postero-anterior and lateral views of a large anepithelial cyst in the region of the right upper lobe.

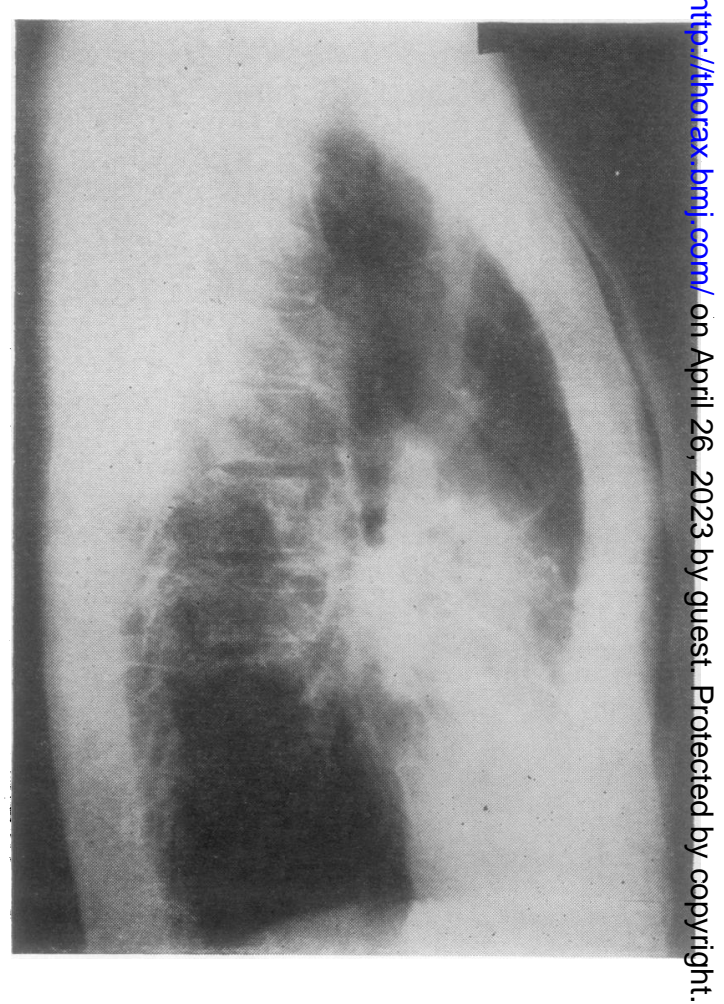




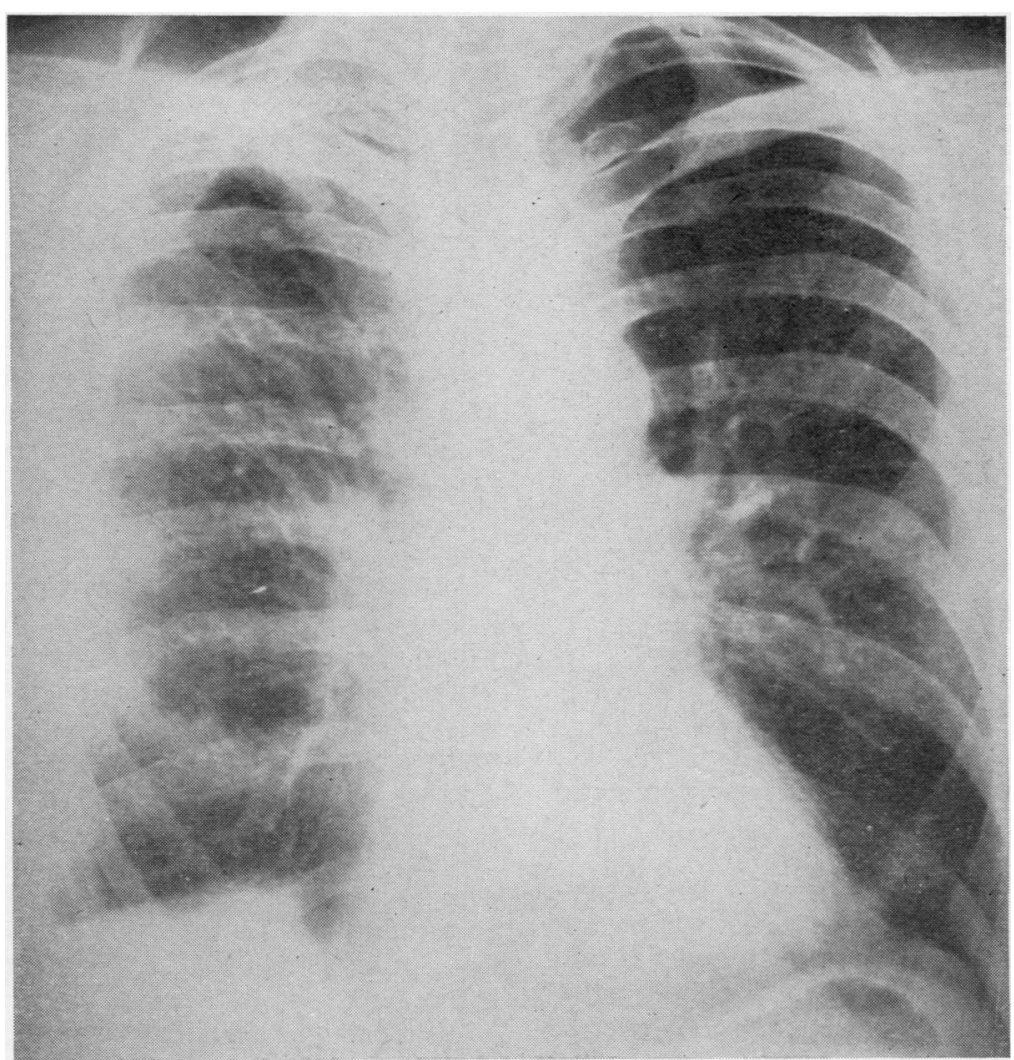

FIG. 2. Post-operative chest film showing good lung expansion.

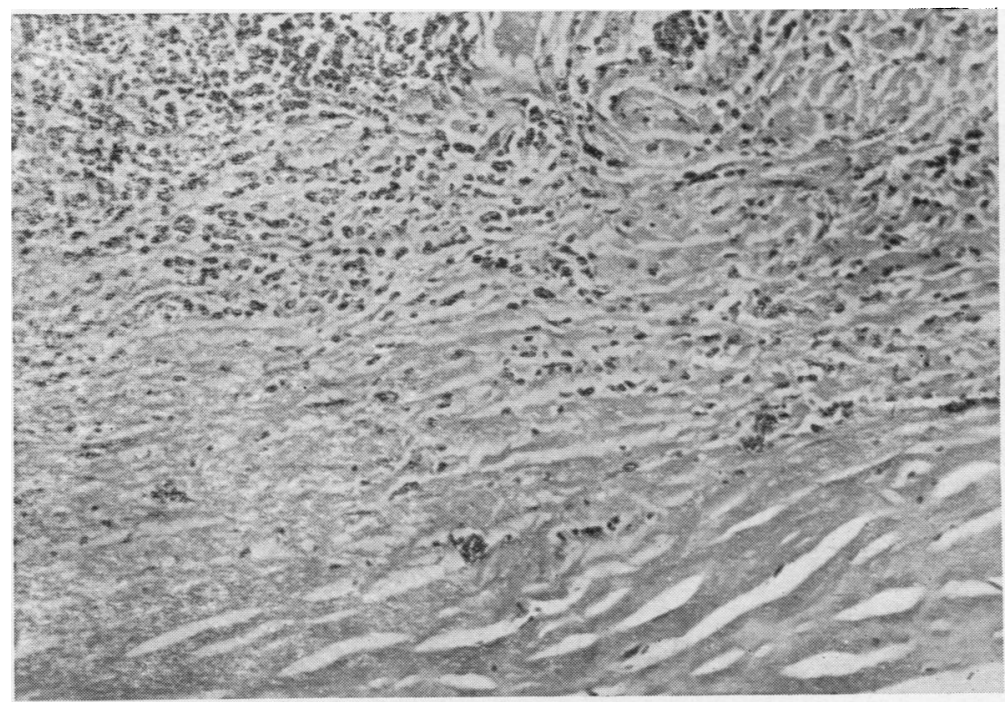

FIG. 3. Microscopical film of the wall of the cyst showing collagen lining with numerous lymphocytes and plasma cells. No epithelial lining. H. and E. $\times 120$. 
TABLE

\begin{tabular}{|c|c|c|c|c|c|c|}
\hline \multirow{2}{*}{$\begin{array}{l}\text { Lung } \\
\text { Volumes }\end{array}$} & \multirow{2}{*}{\multicolumn{2}{|c|}{$\begin{array}{l}\text { Predicted } \\
(\mathrm{ml} .)\end{array}$}} & \multicolumn{2}{|c|}{ Pre-operative } & \multicolumn{2}{|c|}{ Post-operative } \\
\hline & & & $\mathrm{ml}$. & $\%$ & $\mathrm{ml}$. & $\%$ \\
\hline $\begin{array}{ll}\text { V.C. } & \cdots \\
\text { E.R.V. } & \cdots \\
\text { I.C. } & \cdots \\
\text { F.R.V. } & \cdots \\
\text { R.V. } & \cdots \\
\text { T.L.C. } & \cdots\end{array}$ & \multicolumn{2}{|c|}{$\begin{array}{l}4,508 \\
1,497 \\
3,011 \\
4,339 \\
2,842 \\
7,450\end{array}$} & $\begin{array}{r}3,185 \cdot 7 \\
981 \cdot 9 \\
2,356 \cdot 6 \\
3,575 \cdot 0 \\
2,593 \cdot 1 \\
5,93: 0\end{array}$ & $\begin{array}{l}70 \cdot 7 \\
65 \cdot 6 \\
78 \cdot 3 \\
79 \cdot 6 \\
91 \cdot 2 \\
83.0\end{array}$ & $\begin{array}{l}3,703 \\
1,455 \\
2,248 \\
3,719 \\
2,264 \\
5,967\end{array}$ & $\begin{array}{l}82 \\
97 \\
75 \\
86 \\
80 \\
80\end{array}$ \\
\hline R.V./T.L.C. & \multicolumn{2}{|c|}{$44 \%$} & \multicolumn{2}{|l|}{$43 \cdot 7 \%$} & \multicolumn{2}{|l|}{$38 \%$} \\
\hline \multirow{2}{*}{\multicolumn{3}{|c|}{ Mechanics }} & \multicolumn{2}{|c|}{ Pre-operative } & \multicolumn{2}{|c|}{ Post-operative } \\
\hline & & & $\mathrm{ml}$. & $\%$ & $\mathrm{ml}$. & $\%$ \\
\hline $\begin{array}{l}\text { F.E.V. } \\
\text { F.E.V.1 } \\
\text { F.E.V.2 } \\
\text { F.E.V.2 }\end{array}$ & $\begin{array}{l}\cdots \\
\cdots \\
\cdots\end{array}$ & $\begin{array}{l}\cdots \\
\cdots \\
\cdots\end{array}$ & $\begin{array}{l}3,185 \cdot 7 \\
1,549 \cdot 2 \\
2,062 \cdot 0 \\
2,356 \cdot 6\end{array}$ & $\begin{array}{l}48 \cdot 6 \\
64 \cdot 7 \\
74 \cdot 0\end{array}$ & $\begin{array}{l}3,703 \\
1,962 \\
2,530 \\
2,909\end{array}$ & $\begin{array}{l}53 \\
68 \\
79\end{array}$ \\
\hline \multicolumn{3}{|c|}{$\begin{array}{l}\text { Flow rates (1. min.): } \\
\text { Inspiration } \quad . . \\
\text { Expiration } \quad . \\
\text { Air trapping } \ldots \\
\text { O, uptake (ml. min.) } \\
\text { Arterial blood : } \\
\text { pH } \text { PCO }_{2} \text { (mm.Hg) } \\
\mathrm{O}_{2} \text { saturation (\%) }\end{array}$} & \multicolumn{2}{|c|}{$\begin{array}{l}166 \cdot 8 \\
218 \cdot 4 \\
\text { Moderately severe } \\
245\end{array}$} & \multicolumn{2}{|l|}{$\begin{array}{r}259 \\
231 \\
\text { Mild } \\
298\end{array}$} \\
\hline
\end{tabular}

T.L.C. ratio. They also show a noticeable improvement in the mechanics of breathing and of oxygen uptake. The arterial blood is fully saturated with oxygen, indicating a good ventilation/perfusion relationship. There is an over-all improvement in the pulmonary function tests post-operatively.

\section{DISCUSSION}

Descriptions of various lung cysts, their origin, pathology, and treatment are given by Boyden (1958), Shek, Cope, and Myers (1956), Siebens, Grant, Kent, Klopstock, and Cincotti (1957), Herrmann, Jewett, and Galletti (1959), WooMing, Capel, and Belcher (1963), and others. Belcher and Siddons (1954) classified cysts of the lung as (1) bronchogenic cysts ; (2) post-infective cysts ; (3) infantile tension cysts ; (4) anepithelial cysts ; and (5) emphysematous cysts. The cardinal features of these types are as follows:

Bronchogenic cysts are developmental in origin. They are lined with ciliated epithelium, and the wall may contain smooth muscle, cartilage, mucous glands, or elastic tissue.

Chronic lung abscesses appear as thick-walled, fluid-containing cavities which may eventually become epithelialized and may be indistinguish- able from bronchogenic cysts, but the walls of the cavities consist of fibrous tissue only.

Some infantile tension cysts consist of a single cystic space lined with respiratory epithelium; others take the form of a localized emphysema. The exact aetiology is obscure, but the tension element must arise from a check-valve mechanism. In some of them there is a congenital absence of bronchial cartilage.

Anepithelial cysts are essentially unassociated with emphysema. They have no epithelial lining. The cysts may reach very large proportions and almost fill a hemithorax. They are joined to the lung by a narrow pedicle. The walls are thin and translucent, and trabeculae often cross the lumen. The aetiology is uncertain.

Macroscopically emphysematous cysts are similar to anepithelial cysts, but they are either within the pulmonary substance or they project from the lung surface beneath the pleura and are very seldom pedunculated. They are frequently multiple and associated with emphysematous changes in the lung or lobe.

The present case fits into the group of anepithelial cysts. The patient had moderate generalized emphysema of the lung, but that the cyst was not an emphysematous one is indicated by the fact that it had practically no attachment to the lung tissue.

Although the origin of anepithelial cysts is uncertain, Belcher and Siddons (1954) suggested that in view of the fact that they occur at a younger age than emphysematous cysts, and of the coincidence of other congenital lesions, the cysts may be of developmental origin. This is suggested in our case by the presence of abnormal fissures of the lung.

We wish to thank Dr. E. Hapke for the physiological assessments which were performed in Dr. L.R. West's Department, and Dr. R. M. E. Seal for the photograph and pathological report.

\section{REFERENCES}

Belcher, J. R., and Siddons, A. H. M. (1954). Air-containing cysts of the lung. Thorax, 9, 38.

Boyden, E. A. (1958). Bronchogenic cysts and the theory of intralobar sequestration: New embryologic data. J. thorac. Surg., 35, 604, Terrmann, J. W., Jewett, T. C., and Galletti, G. (1959). Bronchogenic cysts in infants and children. Ibid., 37, 242.

Shek, J. L., Cope, J. A., and Myers, G. D. (1956). Giant air cyst(s) as

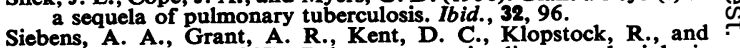
Cincotti, J. J. (1957). Pulmonary cystic disease: physiologic studies and results of resection. Ibid., 33,185 .

Woo-Ming, M., Capel, L. H., and Belcher, J. R. (1963). The results of surgical treatment of large air cysts of the lung. Brit. J. Dis. Chest, 57, 79. 